ANIELA DYLUS

\title{
WYZNANIOWE ZRÓŻNICOWANIE KULTURY GOSPODARCZEJ. O IDEOLOGICZNYM NADUŻYCIU ZNANEJ TEZY
}

\begin{abstract}
Dylus Aniela, Wyznaniowe zróżnicowanie kultury gospodarczej. O ideologicznym nadużyciu znanej tezy [Religion and the differentiation of economic culture forms. On the ideological abuse of the well-known thesis] edited by W. Banach - "Człowiek i Społeczeństwo", vol. XXXVIII, Poznań 2014, pp. 67-80, Adam Mickiewicz University Press. ISBN 978-83-232-2791-5. ISSN 0239-3271.

More than one hundred years ago, Max Weber agued that the Protestant religion, particularly the religious ideas of Calvinism and the Puritan ethic, played a positive role in creating the capitalistic spirit. The article hereby attempts to show that this thesis (the Protestant Ethic Thesis) gradually evolved into different stereotypes. It also appeared to be especially prone to some ideological abuse. The description of these stereotypes and different forms of abuse has been preceded with attempts to answer some questions such as: Is the cultural context of economic life really differentiated with regard to religious ideas? Is Max Weber's thesis timeless? In fact, the results of various kinds of research allow to falsify the thesis given above. It is the real religious faith as such and not its content that is economically significant. However, there are some cultural differences between Catholics and Protestants that are determined by their religious faith. These differences concern rather e.g. their different focus on the value hierarchy or significance attached to satisfying needs.
\end{abstract}

Aniela Dylus, Uniwersytet Kardynała Stefana Wyszyńskiego, Katedra Etyki Gospodarczej i Polityki Gospodarczej, Instytut Politologii, ul. Wóycickiego 1/3, budynek 23, 01-938 Warszawa, Poland.

\section{WSTĘP}

Przed ponad stu laty Max Weber sformułował tezy, które okazały się niezwykle płodne w naukach społecznych. W nawiązaniu do słynnego dzieła Etyka protestancka a duch kapitalizmu ${ }^{1}$ kolejne pokolenia socjologów, ekonomistów i etyków próbują weryfikować lub falsyfikować jego tezy: o fundamentalnym znaczeniu chrześcijańskiego zaplecza kulturowego dla budowy libe-

1 Por. M. Weber, Etyka protestancka a duch kapitalizmu, przeł. J. Miziński, Wydawnictwo Test, Lublin 1994 (pierwsze wydanie oryginału - 1905). 
ralnych instytucji gospodarczych oraz o pozytywnym wpływie protestantyzmu, a zwłaszcza teologii kalwińskiej i etyki purytańskiej, na kształtowanie ducha kapitalizmu. Mimo postępującej sekularyzacji naznaczonego chrześcijaństwem zachodniego kręgu kulturowego sprawa wyznaniowego zróżnicowania kultury gospodarczej ciągle budzi kontrowersje. Jej przedmiotem jest przede wszystkim pytanie, czy protestantyzm i katolicyzm rzeczywiście są głównymi czynnikami przesądzającymi o zasadniczej odmienności wzorów kulturowych oraz stylów i efektów gospodarowania. Znaczenie prawosławia pozostaje przy tym nieco na uboczu teoretycznych kontrowersji, choć samo w sobie mogłoby stanowić interesujące pole badawcze.

Sprawa jest godna namysłu, gdyż odpowiedź na pytanie o występowanie $\mathrm{w}$ przeszłości i przetrwanie do obecnych czasów owego zróżnicowania wcale nie jest jednoznaczna. Nawet jeśli okaże się, że trudno zaprzeczyć występowaniu uwarunkowanych wyznaniowo różnic kulturowych, to w ramach refleksji wokół wzorów kultury gospodarczej interesujące wydaje się ustalenie ich charakteru i tego, czy rzeczywiście są one relewantne w perspektywie rozwoju ekonomicznego. Tym bardziej że podejmując ogólną refleksję „nad polskimi sposobami myślenia o gospodarce, pracy i zarządzaniu”, mamy przecież świadomość, iż „katolicka Polska” jest niemal jednolita wyznaniowo. Wspomniane wyżej tezy Maxa Webera - choć naukowo bardzo płodne - stopniowo obrastały różnymi stereotypami, a co gorsza okazały się niezwykle podatne na ideologiczne nadużycia. Biorąc to pod uwagę, proponuję, aby w niniejszym tekście skoncentrować się właśnie na tych stereotypach i nadużyciach.

\section{ZRÓŻNICOWANIE KONFESYJNE GOSPODARCZEGO KONTEKSTU KULTUROWEGO}

Przywołując tezę Maxa Webera o wpływie protestantyzmu na rozwój kapitalizmu, warto na początku zaznaczyć, że wypowiadał się on o występowaniu owej zależności u samych początków kształtowania się tego systemu ekonomicznego ${ }^{2}$. Zapewne dla pierwotnej akumulacji kapitału kalwińska doktryna predestynacji mobilizująca do maksymalnego wysiłku dla osiągnięcia ziemskiego sukcesu oraz purytańskie cnoty i asceza rzeczywiście nie były bez znaczenia ${ }^{3}$. Dla niektórych badaczy "pozostaje faktem, że po-

\footnotetext{
2 Pisałam o tym wcześniej, por. A. Dylus, Etyka katolicka a duch kapitalizmu, [w:] Religia tożsamość - Europa, red. P. Mazurkiewicz, S. Sowiński, Zakład Narodowy im. Ossolińskich, Wrocław-Warszawa-Kraków 2005, s. 148-160.

${ }^{3}$ Chociaż nawet wokół historycznej weryfikowalności Weberowskiej tezy od dawna toczy się spór. Kwitnące gospodarczo (w XV w.) włoskie miasta, choć pozbawione protestanckiego
} 
czątki kapitalizmu szły w parze z przesunięciem się centrum rozwoju z kra-

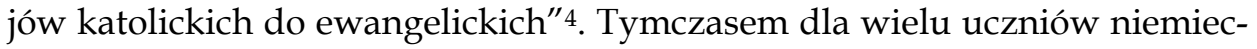
kiego socjologa, a przede wszystkim $\mathrm{w}$ obiegowym rozumieniu, omawiana tu teza ma znaczenie ponadczasowe, a w każdym razie doskonale tłumaczy również współczesne dysproporcje rozwoju gospodarczego i poziomu życia5. Czy rzeczywiście?

Okazuje się, że jednoznaczna odpowiedź na to pytanie wcale nie jest prosta. Janusz Hryniewicz, powołując się na badania przeprowadzone w latach 1981-1986 w trzydziestu krajach, a dotyczące różnic kulturowych między katolikami i protestantami ${ }^{6}$, przyznaje, że ich rezultatem było „niepotwierdzenie się hipotezy zaczerpniętej od Maxa Webera, a dotyczącej różnic $\mathrm{w}$ zakresie etyki pracy i aspiracji związanych $\mathrm{z}$ kształceniem. [...] Potwierdziły się natomiast oczekiwania dotyczące różnych sposobów postrzegania instytucji społecznych". Jednocześnie w innym miejscu swego tekstu, poniekąd zaprzeczając samemu sobie, pisze: „Już Max Weber zauważył różnice osiągnięć gospodarczych obu tych kręgów kulturowych ${ }^{7}$. Są one nadal dość wyraźne". Wbrew przywoływanym wcześniej badaniom, wspomina też o "relatywnym katolickim antyintelektualizmie"8.

Twierdzenie o „nadal dość wyraźnym” konfesyjnym zróżnicowaniu osiągnięć gospodarczych obu kręgów kulturowych można próbować weryfikować statystycznie. Od dawna podejmuje się takie próby ${ }^{9}$. W jednej z nich odwołano się do opublikowanej w 2009 roku listy krajów uporządkowanych według osiągniętego (w 2007 r.) poziomu indeksu rozwoju ludz-

zaplecza kulturowego, uznaje się przecież za kolebkę kapitalizmu. Podobnie w Szwajcarii i Holandii zalążki kapitalizmu były obecne na długo przed rozprzestrzenieniem się kalwinizmu. Zainteresowanych tym sporem można odesłać do bogatej literatury na ten temat, np.: G. Marshall, In Search of Capitalism, Columbia University Press, New York 1982; K. Samuelsson, Protestantyzm a kapitalizm. Krytyka teorii Maxa Webera, przeł. J. Grossfeld, "Znak" 1984, nr 356, s. 897-917; M. Ossowska, Moralność mieszczańska, Zakład Narodowy im. Ossolińskich, Wrocław-Warszawa-Kraków 1985; A. Macfarlane, The Culture of Capitalism, Basil Blackwell, Oxford 1987; Kultura przedsiębiorczości, red. B. Berger, przeł. K. Frieske, Oficyna Literatów „Rój” Warszawa 1994.

${ }^{4}$ L. Jasiński, Ekonomia i etyka, WAM, Kraków 2012, s. 265.

${ }^{5}$ Sądzę, że przypisanie tezie Maxa Webera znaczenia ponadczasowego jest jednym ze stereotypów narosłych wokół niej. Będzie o tym mowa w dalszej części tego tekstu.

${ }^{6}$ Hryniewicz powołuje się na: A. Greeley, Protestant and Catholic: Is the Analogical Imagination Extinct?, „American Sociological Review” 1989, no. 54(4).

${ }^{7}$ Chodzi tu o kulturę mieszczańską i protestancką oraz szlachecką i katolicką.

8 J.T. Hryniewicz, Historyczne przestanki kształtowania się polskiej kultury organizacyjnej oraz jej wspótczesne manifestacje w postawach $i$ doznaniach psychicznych (w niniejszym tomie, s. 13-15).

9 Omawiając dalej dwie $\mathrm{z}$ nich (w których porównuje się siłę ekonomiczną nie tylko krajów katolickich i protestanckich, ale też prawosławnych, islamskich oraz tych, w których dominują religie dalekowschodnie), odwołuję się do: L. Jasiński, op. cit., s. 255-257. 
kiego HDI ${ }^{10}$. Przy uwzględnieniu 75 państw z górnej części listy okazało się, że średni poziom indeksu dla krajów katolickich wynosił 0,901, zaś dla krajów protestanckich - 0,921. Trudno uznać, że ta nieznaczna różnica poziomu indeksu jest mocnym argumentem na rzecz przewagi gospodarczej krajów o tradycji protestanckiej. Tym bardziej że można się spierać i o przydatność badawczą HDI, i o zasadność porównywania tylko 75 państw z listy, i o przyznanie niektórym państwom (np. Holandii czy Niemcom) katolickiej bądź protestanckiej tożsamości.

Wyraźniejsze różnice siły ekonomicznej odsłonił indeks międzynarodowej konkurencyjności danego kraju, ilustrujący zdolność budowy pozycji na rynku światowym. Z rankingu opublikowanego w 2010 roku przez International Institute for Management Development w Szwajcarii wynika, że przeciętne wskaźniki wynoszą: dla krajów o tradycji katolickiej 59,32, zaś dla ewangelickiej - 81,99. Pomijając zastrzeżenia co do konstrukcji tego rankingu, trzeba też - za Leszkiem Jasińskim - zauważyć, iż „pozycję grupy krajów katolickich obniżył słaby wynik Wenezueli". Przesądza o nim nie tyle katolickość tego kraju, ile sytuacja polityczna. Gdyby skrócić listę tylko o to jedno państwo, średni wskaźnik dla krajów katolickich wzrósłby o około 2 punkty ${ }^{11}$.

Trudno nie zgodzić się z wnioskiem wysnutym przez cytowanego tu autora: „Chociaż analiza statystyczna wskazuje na pewną przewagę rozwojową krajów ewangelickich, nie powinno zostać to odczytane jako jednoznaczne rozstrzygnięcie postawionego problemu"12. Podobny pogląd reprezentuje Marcus Noland ${ }^{13}$. Pogłębiona analiza omawianej tu kwestii wskazuje - jego zdaniem - „na pewien związek między przynależnością do organizacji wyznaniowych a wynikami ekonomicznymi". Jednak, jak twierdzi przywołujący jego poglądy Jasiński, Noland „nie uznaje takiej zależności za silną"14. Wręcz przeciwnie, uważa on "pochodzące od Maxa Webera opinie na temat silnej zależności sytuacji gospodarki od religii i dominacji na tym polu protestantyzmu za statystycznie przezwyciężone" 15 .

Przesłanką wysnuwania podobnych wniosków są jeszcze inne badania porównawcze. Otóż, w 2003 roku zaprezentowano w Harvardzie studium Roberta J. Barra i Racheli M. McCleary zawierające wyniki projektu ba-

\footnotetext{
10 Indeks ten jest wypadkową długości trwania życia, jakości edukacji i wielkości PKB na jednego mieszkańca.

11 L. Jasiński, op. cit., s. 257.

12 Ibidem, s. 258

${ }_{13}$ Por. M. Noland, Religion, Culture and Economic Performance, Peterson Institute for International Economics, Washington 2003, cyt. za: ibidem.

${ }^{14}$ L. Jasiński, op. cit.

15 Ibidem, s. 259.
} 
dawczego dotyczące wpływu religii na życie gospodarcze. Badania w 59 krajach prowadzono w latach 1981-1989. Wynika z nich, że kształtowane pod wpływem religii cnoty, takie jak uczciwość, sumienność, pracowitość, oszczędność i otwartość wobec obcych, pozytywnie wpływają na osiągnięcia gospodarcze. Inaczej niż u Maxa Webera, badania pokazują, że znacząca gospodarczo jest żywa wiara religijna jako taka, nie zaś jej treść. Do wzrostu gospodarczego w równej mierze przyczynia się chrześcijaństwo (i katolicyzm, i protestantyzm), co judaizm, islam, hinduizm czy buddyzm - jeśli tylko religie te są naprawdę praktykowane. Wyniki te, jak zauważa Barro, mogą być przestrogą, aby nie wygrywać „dobrych” religii przeciwko „złym”16. Dotyczy to oczywiście również poszczególnych wyznań chrześcijańskich. Dla porządku trzeba jednak odnotować, że teza przeciwna o istotnym znaczeniu protestanckiego kontekstu kulturowego dla osiągnięcia gospodarczego sukcesu, większego niż w ramach katolicyzmu, również ma swoich prominentnych zwolenników wśród przedstawicieli nauk spolecznych ${ }^{17}$. Trudno wyważyć proporcje między nimi. Sądzę jednak, że ci ostatni - przekonani o ponadczasowości Weberowskiej tezy - pozostają dziś w mniejszości.

Nawet jeśli odpowiedź na pytanie, „czy” kontekst kulturowy życia gospodarczego jest do tego stopnia zróżnicowany konfesyjnie, iż wpływa to znacząco na osiągnięcia gospodarcze, brzmi: „raczej nie”, to i tak warto ustalić charakter tych różnic. Właśnie odpowiedzi na pytanie o protestancką i katolicką tożsamość kultury gospodarczej będzie poświęcony kolejny punkt tych rozważań.

\section{PRÓBA IDENTYFIKACJI RÓŻNIC PROTESTANCKIEJ I KATOLICKIEJ KULTURY GOSPODARCZEJ}

Zdając sobie sprawę, że nie ma jednej, protestanckiej bądź katolickiej, kultury gospodarczej, że są one historycznie i geograficznie bardzo zróżnicowane, postawmy mimo wszystko pytanie o ich generalną tożsamość. Pozornie wydaje się, że signum specificum protestanckiego stosunku do działalności gospodarczej jest niezwykłe poszanowanie pracy. Uważa się ją za powołanie Boże. W tym kontekście charakterystyczne jest podobieństwo

${ }^{16}$ Studium R.J. Barro i R.M. McCleary omawia Karl-Peter Schwarz w tekście Die Engel der Nationen, „Frankfurter Allgemeine Zeitung” 7.04.2004.

17 Należy do nich chociażby D.S. Landes. Por. tegoż, Bogactwo i nędza narodów: dlaczego jedni sa tak bogaci, a inni tak ubodzy, przeł. H. Jankowska, MUZA SA, Warszawa 2000, cyt. za: L. Jasiński, op. cit., s. 259. 
w języku niemieckim słów Beruf - zawód i Berufung - powołanie ${ }^{18}$. Ale przecież i w katolicyzmie praca pojmowana jako udział $\mathrm{w}$ dziele stwórczym i zbawczym Boga ma bardzo wysoką wartość.

Już bardziej wyraźny wyróżnik protestantyzmu, nieobojętny gospodarczo, wiąże się z luterańską zasadą sola scripura i obowiązkiem lektury Biblii. Dzięki temu zdecydowanie poszerzyła się umiejętność czytania, np. w XVII-wiecznej Szwecji. Długofalowo niewątpliwie był to znaczący czynnik rozwoju gospodarczego ${ }^{19}$. Choć przywoływane wcześniej badania empiryczne nie potwierdziły rzekomych różnic między katolikami a protestantami w zakresie aspiracji co do kształcenia, to współczesny protestantyzm ciągle z dumą definiuje siebie jako „religię edukacji” (die Bildungsreligion) ${ }^{20}$.

Jak już wspomniano, teza Maxa Webera dotyczyła głównie kalwińskiej wersji protestantyzmu i specyficznej dla niej doktryny predestynacji. Głosi ona, że Bóg z góry przeznacza jednych do zbawienia (a zatem inni skazani są na potępienie), zaś zewnętrznym, widzialnym znakiem owego wiecznego przeznaczenia jest ziemski sukces. Trudno przecenić siłę motywacyjną tej wiary i jej znaczenie dla pierwotnej akumulacji kapitału. Starając się pozbyć wątpliwości co do swego wybraństwa, ludzie podejmowali maksymalny wysiłek gospodarczy, aby ów sukces osiągnąć. Wsparciem takiego nastawienia była rozwijana stopniowo w duszpasterstwie i edukacji etyka purytańska cechująca się dużym rygoryzmem moralnym. Abstrahując od ewolucji tej etyki, od jej różnych odmian i specyfiki geograficzneje21, generalnie szczególnie cenionymi cnotami, zwanymi później „mieszczańskimi”, były: gospodarność, uczciwość, rzetelność, pracowitość, pilność, oszczędność i posłuszeństwo. Pożądana była też asceza i panowanie nad sobą. Natomiast do wad i grzechów szczególnie tępionych przez purytańskich kaznodziei i moralistów należały: ostentacyjna, luksusowa konsumpcja, rozrzutność, życie „na kredyt”, lenistwo i próżniactwo.

18 Jednocześnie zwraca się niekiedy uwagę na wynaturzenie tej idei. W artykule pod wymownym tytułem Reformacja jako deformacja pracy ludzkiej Michał Michalski dowodzi, że za konsekwencję przemian wywołanych reformacją należy uznać współczesne ubóstwienie pracy przez człowieka Zachodu - „Praca staje się formą kultu - swoistą świecką religią”. Autor ten uważa, że właśnie „w etosie protestanckim można upatrywać żyzne podłoże, na którym może się rozwijać nałogowa osobowość pracoholika”, M. Michalski, Reformacja jako deformacja pracy ludzkiej, „Humanizacja Pracy” 2011, nr 1, s. 9-21.

${ }_{19}$ Zwraca na to uwagę Leszek Jasiński, op. cit., s. 264.

${ }^{20}$ Tak określił tożsamość protestantyzmu Robert Leicht, kierujący Akademią Ewangelicką w Berlinie. Por. tegoż, "Wissen, werten, handeln”. Evangelische Bildungsoffensive, „Frankfurter Allgemeine Zeitung" 4.05.2004.

21 Świetną charakterystykę wszystkich tych zagadnień prezentuje Maria Ossowska w klasycznej już pozycji Moralność mieszczańska (op. cit.). 
Już z tej pobieżnej charakterystyki cnót i wad wynika, że nie wszystkie purytańskie cnoty byłyby pożądane i nie wszystkie wady potępiane $\mathrm{w}$ warunkach kapitalizmu postindustrialnego. Protestancki etos tzw. „konsumpcji odroczonej" mógłby okazać się zabójczy dla wzrostu gospodarczego. Właśnie purytańskie wady: wyszukana konsumpcja, rozrzutność, życie „na kredyt", napędzają dziś koniunkturę. W gospodarce opartej na wiedzy pewne przetasowania musiałyby też nastąpić w katalogu pożądanych cnót mieszczańskich. Owszem, ciągle dobrze widziana jest rzetelność, uczciwość czy gospodarność, ale już zamiast pilności, oszczędności i posłuszeństwa od menedżerów i pracowników wymaga się dziś raczej innowacyjności, mobilności i dyspozycyjności.

Ze współczesnych badań, jak wskazuje J. Hryniewicz, wynika nieco inne rozłożenie przez katolików i protestantów akcentów w zakresie wartości znaczących gospodarczo. Podczas gdy katolicy większe znaczenie przypisują sprawiedliwości i równości, protestanci nacisk kładą na wolność i indywidualizm. Ci pierwsi bardziej cenią "ciepłe” relacje, są mocniej związani $\mathrm{z}$ rodziną i różnymi społecznościami, a w związku z tym ostrzej oceniają zachowania podważające więź społeczną (samobójstwa, aborcję, eutanazję, zdrady małżeńskie). Ci drudzy z kolei są bardziej posłuszni prawu, silniej akcentują indywidualną odpowiedzialność i ostrzej oceniają łapówki i kłamstwa. Jest czymś znamiennym, że w sporządzanych przez Transparency International rankingach "czystości” korupcyjnej od lat czołowe miejsca zajmują kraje protestanckiego kręgu kulturowego. Odnotowano też pewne różnice dotyczące wagi przywiązywanej do zaspokajania określonych potrzeb. „W protestanckim kręgu kulturowym na plan pierwszy wysuwają się potrzeby materialne, autonomii i osiągnięć indywidualnych. Z kolei w środowisku katolickim silniej akcentowane są potrzeby bezpieczeństwa i afiliacyjne. [...] W efekcie protestanckie instytucje lepiej służą osiąganiu dobrobytu materialnego, zaś katolickie komfortu psychicznego" 22. Zakładając wiarygodność badań, na które powołuje się cytowany autor, trudno uznać przypisywany katolicyzmowi kolektywizm, zaś protestantyzmowi indywidualizm za stereotypowe etykietki.

Trzeba wreszcie wspomnieć o ciekawych różnicach kulturowych generowanych przez omawiane tu wyznania. Niewątpliwie mają one pewne implikacje gospodarcze. Otóż niezależnie od postępującej sekularyzacji, regiony, na przykład w Niemczech, w których hucznie świętuje się karnawał, prawie dokładnie pokrywają się z obszarami zamieszkiwanymi w większości przez katolików (Nadrenia, Bawaria). Uciechy tego świata i pewna roz-

22 J. Hryniewicz, op. cit., s. 15. 
rzutność nie całkiem bowiem przystają do purytańskiej oszczędności i surowości stylu życia. Trudno też pogodzić kolektywne szaleństwa karnawałowe $\mathrm{z}$ protestanckim indywidualizmem.

Mimo wskazanych tu różnic warto zakończyć tę część naszych rozważań niezwykle cenną konstatacją Marii Jarosz. Otóż, jej zdaniem, nie da się wiarygodnie wyjaśnić pewnych zjawisk, np. bardzo wysokiego zagrożenia samobójstwami wśród protestantów czy wolności od korupcji w państwach skandynawskich, religią traktowaną jako czynnik odizolowany ${ }^{23}$. Także różnice kultury gospodarczej i ewentualne dysproporcje rozwojowe zawsze są wypadkową całego splotu rozmaitych czynników. Doskonałą ilustracją tej tezy może być fakt, że do dziś ani w Szwecji, ani w Belgii nie ma zwyczaju ostentacyjnego uzewnętrzniania bogactwa. Podczas gdy szwedzką powściągliwość skłonni jesteśmy tłumaczyć wpływem kultury protestanckiej, w Belgii, pozostającej w kręgu kultury katolickiej, wyjaśnienia tej powściągliwości trzeba szukać w uwarunkowaniach historycznych, mianowicie długie okresy obcego panowania nauczyły Flamandów i Walonów nierzucania się w oczy ${ }^{24}$.

\section{STEREOTYPIZACJA I IDEOLOGIZACJA TEZY MAXA WEBERA}

Literatura poświęcona stereotypom i procesowi stereotypizacji jest już dziś trudna do ogarnięcia. Nie wchodząc w szczegóły, przyjmijmy tu encyklopedyczną konstatację, że stereotypami nazywa się najczęściej „utrwalone i uproszczone przekonania dotyczące odmiennych grup społecznych"25. Obok takich "heterostereotypów" występują też "autostereotypy", czyli uproszczone przekonania jakiejś grupy o sobie. Ze stereotypami zwykle wiążą się wyraźne konotacje emocjonalne i oceniające. Owe uproszczone przekonania zdobywa się przy tym raczej z wtórnych przekazów niż z bezpośredniego doświadczenia. Są one odporne na zmiany, gdyż pełnią ważne funkcje adaptacyjne i tożsamościowe ${ }^{26}$. Trzeba tu dodać, że procesowi stereotypizacji podlegają również wytwory nauki. Stereotyp może poniekąd pasożytować na pojęciu naukowym, czerpiąc powagę z wiedzy naukowej. Co więcej, „każda koncepcja naukowa [...], kiedy już wejdzie w krwiobieg

${ }^{23}$ Por. M. Jarosz, Głos w dyskusji nt. korupcji jako kwestii kulturowej i systemowej, [w:] Korupcja. Oblicza, uwarunkowania, przeciwdziałanie, red. A. Dylus, A. Rudowski, M. Zaborski, Zakład Narodowy im. Ossolińskich, Wrocław-Warszawa-Kraków 2006, s. 194.

24 Por. L. Jasiński, op. cit., s. 264.

${ }^{25}$ K. Mudyń, Stereotyp, [w:] Encyklopedia socjologii, t. 4, red. K. Frieske, H. Kubiak i in., Oficyna Naukowa, Warszawa 2002, s. 121.

26 Por. ibidem, s. 119. 
kultury [...], zaczyna żyć podwójnym życiem. Dla nielicznych pozostaje [...] konstrukcją pojęciową - dla pozostałych staje się zaczątkiem stereotypu lub ideologii" 27 .

Tak jak stereotyp, tak też ideologia stała się przedmiotem licznych studiów w socjologii, filozofii czy w naukach o polityce. Zdając sobie sprawę z nieostrości i wieloznaczności tego pojęcia, nawiążemy tu do jego pejoratywnego sensu (niewątpliwie jako uporządkowanemu zbiorowi idei przypisuje się też ideologii znaczenie bardziej neutralne). Wydaje się słuszne, aby w naszych rozważaniach odwołać się do podwójnego znaczenia ideologii wskazanego przez Karla Mannheima. Jak zaznacza Zygmunt Bauman, wyróżnił on pojęcie ideologii $\mathrm{w}$ znaczeniu szerszym - po prostu jako wiedzy obciążonej "odchyleniem grupowym”. Jak widać, w tym znaczeniu pojęcie ideologii zbliżone jest do stereotypu. Przy analizie ideologizacji tezy Maxa Webera przydatne może się też okazać pojęcie ideologii „w sensie wąskim”, która „ma strukturę kłamstwa”. Wynika ona „z intencji wprowadzenia adresata $\mathrm{w}$ błąd $\mathrm{w}$ imię interesu grupowego"28. Może nim być chociażby wywołanie dumy z własnych osiągnięć, a tym samym wzmocnienie poczucia grupowej tożsamości. W każdym razie jakaś teza naukowa, aspirująca do bezstronnego zdania sprawy $\mathrm{z}$ obserwowanych faktów społecznych czy zależności między nimi, zostaje $\mathrm{w}$ procesie ideologizacji uproszczona i wypaczona - $\mathrm{i}$ to niezależnie od intencji inicjatora tego procesu.

Właśnie tak ma się rzecz z tezą Maxa Webera o wyznaniowym zróżnicowaniu kultury gospodarczej. Stopniowo ulegała ona procesom stereotypizacji i ideologizacji. Ponieważ o różnicy między ideologią w znaczeniu wąskim a stereotypem decyduje trudna do weryfikacji „intencja wprowadzenia adresata w błąd" lub brak takiej intencji, omówimy te procesy łącznie. Przeświadczenie, że „protestantyzm, a zwłaszcza kalwinizm, służy rozwojowi gospodarczemu, a nawet cywilizacyjnemu, bez porównania lepiej niż katolicyzm”, L. Jasiński umieszcza w „kręgu stereotypów”. Ten stereotyp „przyjmuje dzisiaj postać następującą: kraje protestanckie osiągały w przeszłości i notują obecnie lepsze wyniki ekonomiczne niż kraje katolickie i nie jest to dziełem przypadku". Przesądza o tym wysoka ranga sukcesu wśród wartości protestanckich, zaś koncentracja na przezwyciężaniu grzechu i afirmacja życia monastycznego przez katolicyzm. „W efekcie w gospodarce światowej nadal górują kraje ewangelickie"29. Rzeczywiście, mnóstwa przykładów

27 Ibidem, s. 121-122.

${ }^{28}$ Z. Bauman, Ideologia, [w:] Encyklopedia socjologii, t. 1, red. A. Kojder, K. Koseła i in., Oficyna Naukowa, Warszawa 1998, s. 298. Por. także S. Janeczek, Ideologia, [w:] Encyklopedia katolicka, t. 6, red. J. Walkusz, Towarzystwo Naukowe KUL, Lublin 1993, szp. 1406-1407; M.K., Ideologia, [w:] Stownik politologii, red. B. Walicka, PWN, Warszawa 2008, s. 186.

${ }^{29}$ L. Jasiński, op. cit., s. 254. 
podobnego stereotypu (zwykle jest to „autostereotyp”) można się doszukać w nawiązujących do tezy Maxa Webera tekstach niektórych autorów związanych z protestantyzmem. Dotyczy to zarówno praktyków, jak i teoretyków życia gospodarczego. I tak na przykład Karl-Ludwig Kley, prezes zarządu pewnej wielkiej firmy w Niemczech, deklarujący się jako „przekonany chrześcijanin ewangelik", w jednym z opiniotwórczych dzienników z dumą przypomina ważne osiągnięcia reformacji, a mianowicie propagowanie autonomii i odpowiedzialności osobistej jednostki. Z troską konstatując wrogi gospodarce, samonapędzający się resentyment, wyznaczający dziś kierunek rozwoju Kościoła protestanckiego w Niemczech, ubolewa, że podkopuje on dziedzictwo reformacji: wolność, odpowiedzialność, krytycyzm, otwartość na zmiany. Zamiast tego Kościół ten prowadzi moralizującą krytykę kapitalizmu, wzywa do redystrybucji i przyczynia się do upowszechnienia "mentalności totalnego zabezpieczenia” (Vollkaskomentalität). Abstrahując od trafności tej krytyki, ważne w perspektywie "tropienia stereotypów" jest przeświadczenie Kleya, że wskutek takiego nastawienia rozluźnia się stwierdzone przez Webera pokrewieństwo między etyką protestancką a duchem przedsiębiorczości. To zaś okazuje się zabójcze dla wzrostu gospodarczego ${ }^{30}$. Przytoczone tu poglądy o uniwersalności tezy Maxa Webera wyraźnie wykazują cechy stereotypu. Są one dość typowe dla tej części elit gospodarczych i politycznych, która odczuwa więź z protestantyzmem. Przyjmuje się je za niekwestionowany pewnik. Takiemu stereotypowi ulegają także niektórzy przedstawiciele środowisk naukowych.

Dla przykładu przywołam tu poglądy niemieckiego ekonomisty Helmuta Jenkisa, wyartykułowane już po upadku muru berlińskiego ${ }^{31}$. Zastanawiając się nad przyczynami tzw. cudu gospodarczego $\mathrm{w}$ powojennych Niemczech Zachodnich, dochodzi on do wniosku, że rozstrzygające $\mathrm{w}$ tym względzie nie były wcale czynniki powszechnie kojarzone z tym sukcesem, tj. reforma walutowa, reforma gospodarcza i pomoc w ramach planu Marshalla. Najbardziej istotną rolę odegrała tu natomiast etyka protestancka. Bez protestanckiego "usposobienia gospodarczego", mobilizującego do wierności państwu oraz do rzetelnego wypełniania obowiązków, zwłaszcza zawodowych, cud gospodarczy nie byłby możliwy. Zdaniem Jenkisa nawet bez wymienionych wyżej „przedsięwzięć technicznych” odbudowa gospodarcza zakończyłaby się pełnym sukcesem. Tyle tylko, że być może nastąpiłoby to nieco później.

30 Por. K.-L. Kley, Siehe, das sind die Gottlosen, „Frankfurter Allgemeine Zeitung” 10.07.2013.

${ }^{31}$ Prezentowałam je już wcześniej. Por. A. Dylus, Gospodarka. Moralność. Chrześcijaństwo, Kontrast, Warszawa 1994 (zwł. rozdz. Chrześcijańska inspiracja w gospodarce, s. 81-94). 
Wnioski wysnute przez tego autora na podstawie analizy sytuacji gospodarczej byłej NRD są tak kuriozalne, że pozwalają na zakwalifikowanie ich do ideologii w sensie wąskim. Jenkis przyznaje mianowicie, iż na skutek konsekwentnej ateizacji społeczeństwa wschodniej części Niemiec naruszone tam zostało protestanckie usposobienie gospodarcze. Ponieważ zaś nie zdołano go na szerszą skalę zastąpić „etyką socjalistyczną”, masy robotnicze nie miały wystarczającej motywacji do pracy. „W przeciwnym bowiem wypadku ich wydajność pracy $\mathrm{w}$ porównaniu z wydajnością $\mathrm{w}$ Niemczech Zachodnich nie byłaby aż tak niska". Na szczęście, nie ma podstaw do pesymizmu. Nie jest wykluczone, że w wolnym społeczeństwie pozostałe jeszcze resztki etyki protestanckiej zostaną reaktywowane. Dotyczy to również tych, którzy formalnie nie należą do Kościoła. Odwołanie się do tej pozostałości protestanckiego etosu ponownie może sprawić cud ${ }^{32}$. Albo zaślepieniem, albo właśnie ideologiczną „strukturą kłamstwa” można wytłumaczyć niezauważenie przez Jenkisa absurdów gospodarki centralnie sterowanej jako przyczyn bankructwa socjalistycznego systemu ekonomicznego w NRD.

W państwach demokracji ludowej o tradycji katolickiej, np. w Polsce, zideologizowana teza Maxa Webera tym bardziej okazywała się świetnym alibi tłumaczącym kolejne kryzysy gospodarcze. Jeszcze w latach osiemdziesiątych XX wieku niektórzy politycy, np. PRL-owski minister ds. wyznań Kazimierz Kąkol, na inauguracjach nowego roku akademickiego w Chrześcijańskiej Akademii Teologicznej w Warszawie publicznie ubolewali, że swego czasu w Polsce zwyciężyła kontrreformacja. Odpowiedzialnością za gospodarczą mizerię obarczano właśnie polski katolicyzm. Nawet po 1989 roku artykułowano niekiedy podobne skargi, obrażając się na społeczeństwo za jego przywiązanie do katolicyzmu. Dotyczy to zwłaszcza środowiska "gdańskich liberałów". Niektórzy z nich wyraźnie wyrażali niekiedy brak złudzeń co do kondycji etycznej katolicyzmu. Nie tylko nie spodziewali się po nim etycznego wsparcia dla „wolnej” gospodarki kapitalistycznej, ale byli przekonani, iż zasoby kulturowe katolicyzmu: tradycjonalizm, podporządkowanie autorytetom czy wspólnotowość, są gospodarczo kontrproduktywne. Konsekwentnym rzecznikiem poglądu o antykapitalistycznym katolicyzmie, i to nie tylko polskim, jest Jan Winiecki. Porównując po klęsce wyborczej obozu reform w 1993 roku rozchwianą sytuację polityczną Polski i Litwy, z jednej strony, oraz ustabilizowany układ polityczny Czech i Węgier, z drugiej, co mniej więcej odzwierciedlało zachodnie proporcje, docho-

32 Por. H.W. Jenkis, Der protestantische Einfluß auf den deutschen Wiederaufbau, „Die Neue Ordnung" 1993, H. 3, s. 178-192. 
dzi do zaskakującego wniosku, że genezą tej sytuacji jest zróżnicowanie konfesyjne wymienionych krajów. W Polsce źródłem antykapitalistycznej demoralizacji, oprócz ruchu „Solidarności” (!), jest właśnie... katolicyzm. "Okazał się [on] raz jeszcze w historii czynnikiem utrudniającym prokapitalistyczne przemiany. Jego komunalizm, nacisk na podporządkowanie interesów jednostki interesom wspólnoty, jego niechęć do tworzenia i wykorzystywania bogactwa przez jednostkę [...], był ważnym spoiwem niechęci do «nowego»". W poglądach Winieckiego pojawia się też ideologiczny wątek nostalgicznej apoteozy protestantyzmu i swego rodzaju pretensja do rodaków, że chodzą do kościoła, a nie do zboru. Dowodzi on: „Inaczej rzecz się ma w krajach, gdzie protestantyzm zapuścił korzenie. Indywidualny sukces wyrażony zamożnością nie tylko jest uważany za rzecz normalną, ale nawet za nagrodę za podejmowane starania"33. Mniej pryncypialne, choć stanowcze przeświadczenie o antykapitalistycznej zawartości etycznej katolicyzmu, szczególnie katolicyzmu polskiego, artykułował też Janusz Lewandowski. Uważał, że nie jest on właściwym zapleczem kapitalizmu, gdyż deprecjonuje indywidualizm i nie jest $\mathrm{w}$ stanie wygenerować zaradności gospodarczej. Obawiał się, iż „spotkanie katolicyzmu z próbą budowy kapitalizmu stworzy dylematy nieprzezwyciężalne" 34 . Był sceptyczny „co do roli Kościoła i tradycyjnej polskiej religijności w zadomowieniu rynkowych instytucji i wzorów zachowań" 35 . Jego zdaniem kulturowa gleba gospodarki rynkowej została wyjałowiona nie tylko przez socjalizm, ale też przez katolicką nieufność wobec zysku i przedsiębiorczości. O pewnej ambiwalencji poglądów Lewandowskiego dotyczących etycznej roli katolicyzmu w kształtowaniu kapitalizmu świadczy jego przekonanie, że są takie wartości chrześcijańskie, które "harmonizują z wizją demokratycznego kapitalizmu”. Zaraz jednak dodaje, iż tworzą one „inny zestaw niż ten zakodowany w polskiej tradycji i umacniany przez księdza proboszcza" 36 .

Jak wiadomo, ze stereotypami trudno dyskutować. Są one "«nieprzemakalne», odporne na argumenty i fakty" 37 . W odniesieniu do przywołanego tu "bohatera negatywnego": księdza proboszcza, rzekomo tępiącego wszelką samodzielność, nietolerującego jednostkowej wolności i stawiającego w ten sposób tamę kapitalistycznej transformacji w Polsce, warto jednak przywołać wyniki badań Leny Kolarskiej-Bobińskiej dotyczące stosunku ducho-

33 J. Winiecki, Źródta klęski wyborczej tkwia w czynnikach pozaekonomicznych, [w:] Pięć lat po czerwcu, pr. zb., Centrum im. Adama Smitha, Warszawa 1994, s. 115-116.

34 J. Lewandowski, Liberalizm stosowany, Rozmowa „Przeglądu Politycznego" 1991, nr 1, s. 10.

35 Idem, Kościół a wolny rynek, „Nowa Res Publica” 1993, nr 10.

36 Idem, Czy i jaka centroprawica?, „Przegląd Polityczny” 1992, nr 3, s. 9.

${ }^{37}$ K. Mudyń, op. cit., s. 123. 
wieństwa do integracji europejskiej. Wyraźnie sfalsyfikowały one ten koszmarny wizerunek ${ }^{38}$. W każdym razie budzenie poznawczej wrażliwości i czujności na manipulację twierdzeniami naukowymi mimo wszystko ma sens. Będzie choćby znakiem ostrzegawczym, aby samemu nie ulegać temu niebezpieczeństwu. Wartością dodaną tych rozważań może być właśnie zwrócenie uwagi na możliwość wynaturzenia twierdzeń nauk społecznych.

\section{BIBLIOGRAFIA}

Bauman Z., Ideologia, [w:] Encyklopedia socjologii, t. 1, red. A. Kojder, K. Koseła i in., Oficyna Naukowa, Warszawa 1998.

Duchowieństwo parafialne a integracja europejska, red. L. Kolarska-Bobińska, Instytut Spraw Publicznych, Warszawa 2003.

Duchowieństwo polskie wobec perspektywy integracji europejskiej, red. L. Kolarska-Bobińska, Instytut Spraw Publicznych, Warszawa 1998.

Dylus A., Etyka katolicka a duch kapitalizmu, [w:] Religia - tożsamość - Europa, red. P. Mazurkiewicz, S. Sowiński, Zakład Narodowy im. Ossolińskich, Wrocław-WarszawaKraków 2005.

Dylus A., Gospodarka. Moralność. Chrześcijaństwo, Kontrast, Warszawa 1994.

Greeley A., Protestant and Catholic: Is the Analogical Imagination Extinct?, "American Sociological Review" 1989, no. 54(4).

Hryniewicz J.T., Historyczne przestanki kształtowania się polskiej kultury organizacyjnej oraz jej wspótczesne manifestacje w postawach i doznaniach psychicznych, "Człowiek i Społeczeństwo" 2014, t. 38.

Janeczek S., Ideologia, [w:] Encyklopedia katolicka, t. 6, red. J. Walkusz, Towarzystwo Naukowe KUL, Lublin 1993.

Jarosz M., Głos w dyskusji nt. korupcji jako kwestii kulturowej i systemowej, [w:] Korupcja. Oblicza, uwarunkowania, przeciwdziałanie, red. A. Dylus, A. Rudowski, M. Zaborski, Zakład Narodowy im. Ossolińskich, Wrocław-Warszawa-Kraków 2006.

Jasiński L., Ekonomia i etyka, WAM, Kraków 2012.

Jenkis H.W., Der protestantische Einfluß auf den deutschen Wiederaufbau, "Die Neue Ordnung" 1993, H. 3.

Kley K.-L., Siehe, das sind die Gottlosen, „Frankfurter Allgemeine Zeitung” 10.07.2013.

Kultura przedsiębiorczości, red. B. Berger, przeł. K. Frieske, Oficyna Literatów „Rój”, Warszawa 1994.

Landes D.S., Bogactwo i nędza narodów: dlaczego jedni są tak bogaci, a inni tak ubodzy, przeł. H. Jankowska, MUZA SA, Warszawa 2000.

Leicht R., "Wissen, werten, handeln”. Evangelische Bildungsoffensive, „Frankfurter Allgemeine Zeitung" 4.05.2004.

Lewandowski J., Czy i jaka centroprawica?, „Przegląd Polityczny” 1992, nr 3.

Lewandowski J., Kościót a wolny rynek, „Nowa Res Publica” 1993, nr 10.

38 Por. Duchowieństwo polskie wobec perspektywy integracji europejskiej, red. L. Kolarska-Bobińska, Instytut Spraw Publicznych, Warszawa 1998; Duchowieństwo parafialne a integracja europejska, red. L. Kolarska-Bobińska, Instytut Spraw Publicznych, Warszawa 2003. 
Lewandowski J., Liberalizm stosowany, Rozmowa „Przeglądu Politycznego” 1991, nr 1. M.K., Ideologia, [w:] Stownik politologii, red. B. Walicka, PWN, Warszawa 2008.

Macfarlane A., The Culture of Capitalism, Basil Blackwell, Oxford 1987.

Marshall G., In Search of Capitalism, Columbia University Press, New York 1982.

Michalski M., Reformacja jako deformacja pracy ludzkiej, „Humanizacja Pracy” 2011, nr 1.

Mudyń K., Stereotyp, [w:] Encyklopedia socjologii, t. 4, red. K. Frieske, H. Kubiak i in., Oficyna Naukowa, Warszawa 2002.

Noland M., Religion, Culture and Economic Performance, Peterson Institute for International Economics, Washington 2003.

Ossowska M., Moralność mieszczańska, Zakład Narodowy im. Ossolińskich, WrocławWarszawa-Kraków 1985.

Samuelsson K., Protestantyzm a kapitalizm. Krytyka teorii Maxa Webera, przeł. J. Grossfeld, „Znak" 1984, nr 356.

Schwarz K.-P., Die Engel der Nationen, „Frankfurter Allgemeine Zeitung” 7.04.2004.

Weber M., Etyka protestancka a duch kapitalizmu, przeł. J. Miziński, Wydawnictwo Test, Lublin 1994.

Winiecki J., Źródła klęski wyborczej tkwia w czynnikach pozaekonomicznych, [w:] Pięć lat po czerwcu, pr. zb., Centrum im. Adama Smitha, Warszawa 1994. 